\title{
Voces pancaribeñas en América Central: Anacristina Rossi y Limón Reggae ${ }^{1}$
}

\section{Carol Pearson ${ }^{2}$}

North Dakota State University, Estados Unidos

\begin{abstract}
resumen
En Limón Reggae, la autora describe las experiencias de una protagonista que no tiene entrada en ningún grupo: nación, raza o grupo político. Son representaciones de las comunidades afrocaribeñas junto con la lucha revolucionaria en El Salvador y las experiencias de los niños de la calle. En After Exile, Amy Kaminsky plantea la presencia de imágenes corporales en la obra de muchos escritores latinoamericanos exiliados o expatriados. Rossi explora situaciones desesperadas centroamericanas y mundiales, junto a una lucha deresistencia.
\end{abstract}

\begin{abstract}
In Limón Reggae, the author describes the experiences of a protagonist whonever finds acceptance or inclusion in any group, whether that of nation, ethnicity or politics. We find representations of Afro-Caribbean communities along with the revolutionary struggle in El Salvador and the experiences of present-day street children. In After Exile, Amy Kaminsky acknowledges the presence of images of the body in the work of many Latin American writers who have been exiled or have lived expatriate lives. Rossi explores desperate situations, both Central American and worldwide, together with aresistance struggle.
\end{abstract}

Palabras clave: novela costarricense contemporánea, novela política, cultura afrocaribeña

Keywords: contemporary Costa Rican novel, political novel, Afro-Caribbean culture

1 Ponencia presentada en el XX Congreso Internacional de Literatura Centroamericana (ciLca) 2012. Recibido: 3 de abril de 2011; aceptado: 12 de mayo de 2011.

2 Correo electrónico: Carol.Pearson@ ndsu.edu

$$
L_{\text {etras }} 49 \text { (2011), ISSN 1409-424X }
$$


Después de escribir sobre obras de autoras en situaciones de emergencia de la década de 1980, he querido explorar y reconocer experiencias recientes de escritores centroamericanos que se vieron metidos en vidas expatriadas o de exilio. Con la atención que se ha prestado a las obras que han surgido de esas situaciones de emergencia, la pauta indica que sigamos vigentes de emergencias posteriores.

Una pista por seguir es el análisis de Amy Kaminsky y su consideración de las experiencias de los autores (en su caso) del Cono Sur $^{3}$. Resalta el nexo entre la escritura sobre estas experiencias y las imágenes corporales. En After Exile: Writing the Latin American Diaspora, Kaminsky hace hincapié en el uso del término «exilio» no como metáfora generalizada, sino como término que describe la experiencia agonizante, padecida corporalmente, del exilio literal: «Exile and all the processes related to it have a material component, and that component is felt, experienced, and known throughout the body» (xi). Kaminsky continúa: «without the emplaced human body, there is nothing to know or represent about exile and its aftermath» (xi); y sigue: «I am trying to hold on to the material: exile as a lived reality; language as produced in, and received by, the body» (xvi). La obra de Rossi ofrece una reconstrucción de la historia a la vez nacional y personal.

Kaminsky también destaca la importancia de la memoria: «My own belief is that the stories of exile [and expatriate life], which include within them the terrible stories of torture, disappearance, prison, and loss, need to be told and remembered» (xviii). Como escritora una y otra vez expatriada, Rossi, en La loca de Gandoca, Limón Blues y Limón Reggae ${ }^{4}$, describe aspectos, corporalmente imaginados, de las memorias de sus comunidades.

3 Amy Kaminsky, After Exile: Writing the Latin American Diaspora (Minneapolis: Minnesota, 1999).

4 Anacristina Rossi, La loca de Gandoca (San José: EDUCA, 2000); La loca de Gandoca/The Madwoman of Gandoca Terry J. Martin (trad.) (Lewiston, NY: Edwin Mellen, 2006); Limón Bluse (San José: Santillana, 2002); Limón Reggae (San José: Legado, 2007). 
¿Cómo se muestran estos temas en las tres novelas? Aquí se otorgan representaciones delas comunidades afrocaribeñasenCostaRicaa lo largo de los siglos xix y xx. Estas novelas de una escritora originaria de la región, incluyen voces masculinas y femeninas que perfilan algunasricas experiencias y la historia de estas comunidades que han sobrevivido durante muchos años en la costa oriental. Vemos la imagen de estos pueblos vibrantes, intelectuales, y creativos con visiones y proyectos muy sofisticados. Estas comunidades empezaron en el siglo xix con varias olas deemigración ${ }^{5}$ ¿ ¿Cómoexpresan, enlasnovelas, estas voces su vida expatriada, su historia y sus conexiones corporales? ¿Cómo entreteje Rossi el espacio público/privado y la resistenciay el cuerpo? La obrarossiana,leídaenelcontexto,nosperfilalosnexospolíticos/sexuales y nos pinta varias formas de enfrentar la opresión.

En La loca de Gandoca, el tema gira en torno al destierro y al exilio; en contraste con el caso de una persona desterrada, tenemos la situación en que se despoja y se destruye la tierra de las personas; es la tierra que recibe la acción. Entre los temas de esta novela están los siguientes: 1) una conexión entre la tierra y lo personal; 2) tal vínculo contrasta con la relación de los empresarios y la tierra (y también en contraste con la corrupción por parte de los oficios del gobierno involucrados); los dos grupos se alejan de la tierra; 3) la relación entre las luchas personales en la vida de la protagonista en cuanto al conflicto público y sus desastres personales; 4) el uso del idioma y la afirmación de la tierra como base de la autenticidad y del poder con que ella puede luchar; y 5) muchas imágenes corporales en la obra rossiana representan el cuerpo como el sitio de abuso y también como arma de la resistencia.

5 Como dice Sofia Kearns: Afro-Caribbeans from Panama (Colombia) and Nicaragua hunted sea turtles on the Costa Rican coast from the early years of the 19th century, eventually establishing permanent settlements at Cahuita, Puerto Viejo..., Punta Uva..., Manzanillo, and Punta Mona... Later in the century, many Jamaicans came to work for the railroad and the banana plantations. Today, Afro-Caribbean people constitute $43 \%$ of the population of Limón... Their traditional language is Mecaitelia, the local English dialect, which they maintain alongside Standard English and Spanish (La Loca de Gandoca, 2006, 4). 
En sus esfuerzos para proteger el refugio, Daniela se dirige a las palabras y las memorias; afirma la creencia en el lenguaje como manera de preservar las memorias:

Verlo bien y contarlo, para que conste que una vez existió el paraíso. Me despidieron del Ministerio y me enajenaron la comunidad, los intereses comerciales parecen triunfar sobre la salud, la belleza, la vida. Ahora solamente «me queda la palabra» [Antonio Machado]. Y como dice Beto, un negro de Cahuita, 'la palabra es la historia'. La palabra es la historia mientras se registra por escrito en algún lado. ¿En dónde dejar constancia de la canción melancólica del curré? ¿Quién la ha oído? (102).

Sabemos más del contexto de las comunidades de afrocaribeñas costarricenses en Limón Blues. Ambas novelas abren espacio a las voces silenciadas. La loca de Gandoca les da voz a la tierra en sí, a los animales, las plantas y al mar; también a los indígenas y a afrocostarricenses. En Limón Blues, las voces son de los afrodescendientes a lo largo de los siglos. En la época que corresponde al fin del siglo xix, el gobierno costarricense les impedió a los afrocaribeños pasar por las montañas para entrar en el resto del país. A pesar de su pobreza y esta segregación geográfica, pervivían las comunidades afrocaribeñas de esta costa, había conciertos, discursos, una vida literaria y educada. Había mucho apoyo a los proyectos de Marcus Garvey, y diversas formas de activismo político. Rossi escribe con el propósito de recordar y archivar la memoria de esta gente ${ }^{6}$.

6 En los años cincuenta viví en 'el Atlántico', como se le decía entonces el Caribe costarricense. Port Limón estaba unido o más bien desunido del resto del país por ocho horas en un tren que las lluvias interrumpían. En Limón vivía una gente fascinante que hablaba un inglés exquisito, se vestía de modo espectacular, cantaba cosas extraordinarias y tenía rituales secretos en unos sitios llamados logias. Eran de religión protestante y su autoridad era la reina Isabel de Inglaterra o la U.N.I.A.: el movimiento de Marcus Garvey. Sus actividades preferidas eran la declamación, el canto y el baile. Sus deportes, el cricket y las carreras de caballos. En 1973 dejé Costa Rica y cuando a mi regreso, quince años después, visité Limón, me quedé muy asombrada. ¿Dónde estaba aquella gente, aquel esplendor? ¿Lo había inventado mi imaginación de niña? No, no era mi imaginación. Ese mundo yacía allí, perfectamente documentado, en la Biblioteca Nacional de Costa Rica, en los periódicos de Limón en inglés (Limón Blues, 417). 
En contraste con las memorias de estas comunidades recuperadas/archivadas por Rossi, se dice que el gobierno costarricense nunca considera, ni reconoce, a las mujeres, a los negros o a la naturaleza. Como afirma Kearns: «[Rossi's] voice questions Costa Rican patriarchy and its assumption that nature, women, and the minority populations of Limón are at best secondary entities subordinate to the interests of the white male ruling class of the Central Valley» ( $\mathrm{La}$ loca, 2006, 2).

Además de lo ecológico, consideramos en la obra rossiana varias imágenes corporales, incluso la fundadora de Nanah. En Limón Blues, seguimos la vida de Orlandus Robinson, originario de Jamaica, que llega joven a Limón para establecer su finca de bananos, siguiendo los pasos de su madre Nanah y para ayudar a su familia en Jamaica, pues su padre está enfermo. En Limón Blues, las imágenes corporales establecen la presencia de estos afrodescendientes en la historia de Costa Rica.

Después de escribir sus dos primeras novelas, Rossi amplia la visión al escribir Limón Reggae. En la obra hay varios ejemplos en las experiencias de la protagonista de padecer corporalmente del cuerpo femenino como víctima. Como joven universitaria, la protagonista Laura/Aisha es seducida por un profesor/activista. Roberto es uno de sus profesores y también un líder de un grupo denominado la izquierda divina. Un día se tropezaron y van a un café a charlar. Al fin de la plática, Roberto dice: «Tengo que irme pero esta conversación está interesante, ¿la quieres seguir mañana?... Te invito a comer a mi casa, te recojo aquí en la soda mañana a las siete» (81). El próximo día, en su casa, Roberto le dice:

Ayer me dijiste que estabas cansada de intelectualidad política y que tenías muchas ganas de pasar a la acción... no estás lista para esas actividades... hay otras mejores, y alargó el brazo y le tocó la mejilla respirando fuerte. Eso que estaba haciendo no iba. No iba con lo poco que tenían de conocerse y menos aún con lo que ella sentía, o 
con lo que ella no sentía. No iba pero lo estaba haciendo... Roberto no la acariciaba. La empezó a desvestir... La vio desnuda y se le tiró a chuparle los pechos y se los lamía cuando Laura sintió que algo duro y delgado le abría la entrepierna, avanzaba y la rompía... Y un minuto después él daba un gritito y se desplomaba como muerto. Y ella fría, desconcertada, viendo el cielorraso (84).

Como le contó Laura a su amiga más tarde: - Y lo peor es que el hijueputa culo tuvo la cáscara de volverse y preguntarme «Te gustó?» «Me puse a llorar» (84). Cuando Roberto vio la sangre, estaba asombrado e inmediatamente la llevó a casa; nunca más miró a ella directo en sus ojos.

Otro ejemplo de cuerpo como blanco de abuso físico ocurre al final del relato. A Laura/Aisha le ponen tatuajes en los senos, durante su rato con la pandilla de jóvenes que incluye a su hijo adoptivo, Toño. Aisha está con una compañera Mai, después de haber escapado de Toño y su grupo. Aisha y Mai están platicando sobre el fenómeno de «los conductos»:

Aisha está muy nerviosa, Mai se dice que esa no era el objetivo, tiene que calmarla. Le propone que se metan al jacuzzi... Aisha se quita la blusa de un tirón, no lleva sostén y Mai ve sus pechos todavía erectos pero... «QQué te pasó?» pregunta atónita. «Son tatuajes», dice Aisha. Mai se sienta en la cama, se echa contra el respaldar, respira hondo. Aisha le pregunta « $i$ Te horroriza?» «No, no me horroriza. Pero sí me impresiona» (287).

Después de entrar al jacuzzi, Aisha le cuenta a Mai su encuentro con Toño. A lo largo de la novela, Laura/Aisha es víctima de la exclusión a causa de su cuerpo, marcado con su herencia mezclada (libanesa/mulata/costarricense). Al principio, Laura/Aisha está muy interesada en el trabajo de los activistas jóvenes de los afrodescendientes de Limón. Pero la excluyeron por no tener sangre negra suficientemente pura. El grupo habla del proyecto de fundar 
un periódico. Laura comunica su deseo de participar a uno de los compañeros más en simpatía con ella:

Pero de pronto cambiaron el tema y hablaron de hacer un periódico. A Laura le gustó mucho la idea. Ya estaba media tapis y alzando un poco la voz le dijo a Maikí: «Yo también quiero ayudar con el periódico. Desde San José...» Maikí sonrió pero no le contestó. Entonces Laura subió más la voz y repitió la oferta, sólo que esta vez se dirigió a todos, no sólo a Maikí. Tampoco la escucharon... Y agarró una cuchara y golpeó su botella y gritó «Hey, friends, listen, yo necesito trabajar con ustedes en el periódico». Y Sylvia... se volvió y la miró con sus ojos redondos llenos de desprecio. Pero no se dirigió a ella. — ¿Quién puede explicarle a esta paña cómo son las cosas? —dijo. Reinaldo termina de bajar un trago de ron y se volteó hacia Laura: -This is your last day with us.

- Por si no entiende inglés, traduzco. Mire, este fue su último día con nosotros-le dijo Sylvia a Laura.

- No sean tan groseros, están violando el primer punto de atención which is to be polite- protestó Ahmed.

- To be polite to our people, not to paña people -le ladró Sylvia.

Laura quería que se la tragara la tierra. Qué humillación. Tenía que levantarse y salir corriendo. Pero no podía...

- Lo que ellos quieren decir -le dijo Ahmed con dulzura — es que ya sos revolucionaria y tenés que buscar tu propio camino.... Habibi, tenés que buscar tu propio grupo. En este momento en CoRev sólo podemos admitir afrolimonenses porque nuestras acciones van a tener objetivos raciales (58).

Ella reacciona con una afirmación de lo que pertenece a ella y lo que no se la puede quitar:

a pesar de esa noche terrible nadie le podía quitar lo que ellos le habían dado, lo que ellos le habían enseñado, que la revolución es un cambio interior, que nadie es propiedad de nadie, que toda mujer tiene derecho a elegir su destino, que no se debe usar la palabra 
'hombre' para referirse a toda la humanidad, que los niños no son posesiones, que si un gobierno no permite la creatividad hay que traérselo abajo (59).

Muchos años después, luego de participar en la guerra en El Salvador, Aisha/Laura y el hermano de Ahmed, Raymond, se encuentran y se enamoran: «Raymond era el único hombre que le había dado amor entero, recio. Le propondría que vivieran juntos un tiempo en Nueva York» (262). Aisha estaba esperando la llegada de Raymond antes de salir juntos cuando llegó a visitarla Solange, la hermana de Raymond y Ahmed:

No había terminado Aisha de abrir cuando ya estaba adentro diciendo, 'Voy a ser directa, los afro-descendientes no somos los paña, que... nunca se atreven a decir la verdad. Y la verdad es esta: a todos, oí bien, a todos, a mi familia, a mí, a nuestros conocidos y amigos, nos molesta que seás la novia de Raymond. Lo intentaste con Ahmed, y no pudiste, ¿verdad? A las mujeres afro-descendientes nos parece vergonzoso que las blancas persigan a nuestros hombres'. Fueron ráfagas de metralleta. Seguía: 'Sos bonita y joven. Tus pinturas son buenas. Estoy segura que podés encontrar marido paña fácilmente.' A punto de autocontrol Aisha respondió, 'Solange, yo no perseguí a tu hermano. Nos queremos, eso es todo. Yo no lo obligo a estar conmigo'. 'Ustedes las blancas los envuelven con sus artimañas'. 'Yo no he usado artimañas'. 'Sí, las usás pero ni siquiera te das cuenta, Raymond llega en cinco días y ya aquí se nota, ya tenés todo listo para recibirlo, la comida, la casa. Ustedes los consienten, los chinean, los envuelven. Nuestros hombres saben que nosotras somos dignas, liberadas, no les cocinamos cuando ellos lo piden, no les lavamos la ropa, somos iguales que ellos, no establecemos relaciones de servidumbre. En cambio ustedes sí, y eso es lo que a ellos en el fondo les gusta. Es todo muy asqueroso'. 'Oíme, Solange, en primer lugar yo no soy blanca, vos me conociste y conociste a mi tía, soy medio árabe y mi papá, vos lo has visto, es casi mulato...' ‘Qué no sos blanca? Laura, vos representás la blancocracia, como decía 
Garvey, y talvez lo peor de ella, la parte de abajo. Listen now, hands off my brotha!' Solange lo dijo gritando y salió (262-3).

Aisha queda «paralizada» y posteriormente le escribe una carta a Raymond y sale, sabiendo que nunca van a encontrar la aceptación como pareja. Pero también, ella contempla los motivos históricos para esta tragedia personal:

Entonces, esto es lo que logró este país al definirse como blanco ante los negros y los indios: negar el mestizaje, romper los puentes. Aisha tuvo esa visión muy académica y clara, y supo que por eso, sólo por eso, Solange tenía razón. Como ella no era de la comunidad afroantillana tenía que cargar con la culpa histórica. Y en diez minutos, y sola, no la pudo lavar. Pero tampoco en cincuenta años de trabajo podría, pensó. Solange nunca se iba a dejar convencer y le haría la vida imposible por un asunto de principios. Esa era la realidad (263).

En contraste con los episodios de abuso corporal, Laura/Aisha experimenta y usa el cuerpo como arma. Un ejemplo es el encuentro con Domingo, uno de los revolucionarios en El Salvador. Cuando Domingo traicionó a ella y a sus compañeros, con el resultado de varias muertes, Aisha elimina a Domingo, utilizando su muy sensual cuerpo y la atracción que Domingo muestra hacia ella. Después de la traición de Domingo, Aisha lo persigue clandestinamente. Se aloja con su prima, Reina, y se prepara:

Sabe que debe verse un poco puta, la ocasión lo exige, pero lo que verdaderamente la sorprende es la irrupción de su feminidad... Pero no es sólo [un sex appeal] árabe. Los ojos grandes, oscuros y llenos de brillo con las pestañas crespas le deben algo a su papá. Igual la piel morena, tersa y lisa... Igual el pelo espeso, ondeado... Y ese cuerpo alto, donde los hombros anchos y los pechos contrastan con la delgadez. Las piernas, largas, llenas y torneadas, las piernas de la tía Maroz, adquieren una tensión retadora con los altísimos tacones (162). 
Ella y Domingo se reunieron en un restaurante, y después, poco a poco, él «empieza a confesar lo que hizo. ... le dice que él ... se cansó, que se dio cuenta de que la victoria no es para mañana, ... que eso lo desmoralizó, ..y él quiere ver a sus padres contentos antes que envejezcan...» (163). Cuando sale al baño, Aisha echa unas pastillas en su vaso de Drambuie. Luego, en casa, cuando Aisha sale al baño, Domingo se duerme, y Aisha «retuerce una toalla y poco a poco se la mete en la boca a Domingo... Aisha lo inmoviliza, pone uno de los almohadones contra su cara y lo mantiene así hasta que el cuerpo de Domingo se afloja» (165).

No es que no hay consecuencias emocionales para Aisha. Regresa con los guerreros; trabaja con ellos; Fernando (un líder) y ella se enamoran. Se entera de las muertes de los líderes muy queridos, Héctor, Aurora, y Luz; su hijo adoptivo Toño se vuelve un correíto, y luego no regresa, probablemente se muere. Aisha empieza a rodar con el viento del sur (una posibilidad que aprendió de las mujeres toltecas ${ }^{7}$ ) hasta llegar a otro campamento muy abajo en las montañas. Eventualmente regresa donde su madre y su tía Maroz y pasa casi dos años recuperándose dentro de su cuarto.

Pero es el efecto corporal de la música reggae el que le presta a Aisha un gran apoyo y la más confiable fuerza. En una conversación con el viejo compañero, Maikí:

le dice, 'Veo que a usted le sigue gustando el reggae roots.' Aisha contesta, 'Sí, es una música ecuménica'. A Maikí le parece raro que Laura use esa palabra... Como si le leyera el pensamiento Aisha le dice, 'Sabe, Maikí, el reggae es capaz de unirnos a todos porque tiene el backbeat, ese compás atrasado, como el ritmo revival, el reggae heredó ese silencio de poder y de gloria'. ... 'El reggae hace aflorar

7 Es Toño que le llama la atención a las toltecas: 'Mama, mirá, las mujeres'....'dicen que son las toltecas'. Aisha no las veía. Pero sí las oyó. Claramente dijeron: 'El viento del Sur es de la tierra y es para rodar, el del Oeste es para hundirse en una misma, el del Norte para actuar de inmediato y el del Este para renovarse'. Se abrió un largo silencio y después otra dijo 'Ya nosotras nos vamos, usted use los vientos' (183). 
lo mejor de los seres humanos. Rastafari es muy bueno también. ... Raymond es el único afrodescendiente que no me rechazó, y fue porque era rastafari, rastafari y el reggae son ecuménicos' (281).

La noche en que ella y Raymond se enamoran tiene que ver con el poder del reggae y la recuperación física y emocional de Aisha:

se lanza a la pista y se confunde con los cuerpos oscuros y elásticos, el ritmo los une, el backbeat del reggae los conecta con la tierra en una unión por encima de las disensiones, el backbeat les reparte un indecible poder, crea un espacio de silencio y una hondura de gloria... Baila en trance un reggae donde Marley es eterno... Entre los cuerpos oscuros Aisha baila en trance la canción magnífica cuando una mano húmeda toma su mano. Es un negro alto y joven, un muchacho bellísimo de largos rizos, dreads... el muchacho la atrae hacia él y con el otro brazo le rodea la cintura y de pronto están bailando juntos, muy juntos. El olor de su piel la despierta y la emborracha. La mano tibia que la enlaza se vuelve caliente en su cintura, siente las caderas y las piernas del muchacho moverse con las de ella en una deliciosa concatenación...Que no termine nunca esta reggae que nos ha permitido acercarnos, olernos, tocarnos, piensa Aisha... y en los últimos compases él le pregunta su nombre, ella duda un momento, dice: «Laurencia, ¿y vos?» «Raymond», y al decirlo él la estrecha más aún, una humedad le estalla en la raíz de los muslos y la envuelve su calor, casi dos años dormida y ahora otra vez ese brío en la sangre (198-99).

Al final de la novela, Mai, mujer de setenta años, y Aisha deciden salir en busca de Toño, para impedir la pesadilla: «Mai dice: 'Desde hace rato Fede teme el momento en que el terrorismo o los conductos de armas usen a los pandilleros» (290). Los tres quieren encontrar a Toño para parar «el contacto que está haciendo» (290), porque «puede que estén simulando un contacto entre las maras y el terrorismo antigringo» (290). Al salir en el coche, «Aisha cierra los 
ojos y se hunde en el ritmo, en el backbeat del reggae, en el amado silencio de poder y de gloria» (291).

Las novelas de Rossi incluyen aspectos sobre el abuso corporal como parte del dominio ejercido por el gobierno y el primer mundo. Pero otro aspecto de la obra rossiana representa el uso del cuerpo como arma de resistencia y de autonomía. Así con esta especie de vínculo entre el cuerpo femenino y la comunidad, se revela a la vez la victimización junto con la victoria de la resistencia y la sobrevivencia. 